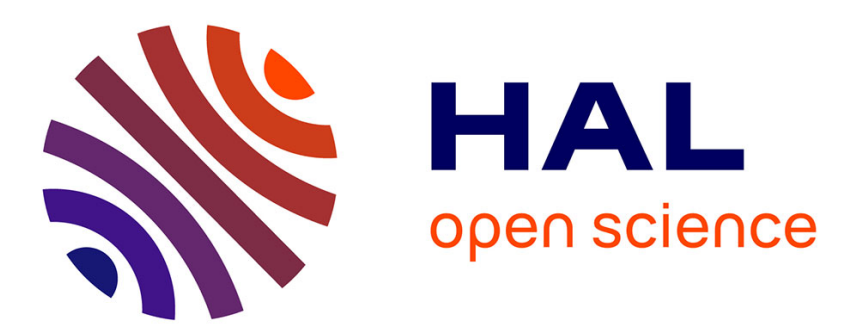

\title{
1,1,4,4-Tetracyanobutadiene-Functionalized Anthracenes: Regioselectivity of Cycloadditions in the Synthesis of Small Near-IR Dyes
}

Clotilde Philippe, Anh Thy Bui, Sabrinah Batsongo-Boulingui, Ziemowit Pokladek, Katarzyna Matczyszyn, Olivier Mongin, Loïc Lemiègre, Frédéric Paul, Trevor A Hamlin, Yann Trolez

\section{To cite this version:}

Clotilde Philippe, Anh Thy Bui, Sabrinah Batsongo-Boulingui, Ziemowit Pokladek, Katarzyna Matczyszyn, et al.. 1,1,4,4-Tetracyanobutadiene-Functionalized Anthracenes: Regioselectivity of Cycloadditions in the Synthesis of Small Near-IR Dyes. Organic Letters, 2021, 23 (6), pp.2007-2012. 10.1021/acs.orglett.1c00136 . hal-03157427

\section{HAL Id: hal-03157427 \\ https://hal.science/hal-03157427}

Submitted on 13 Jul 2021

HAL is a multi-disciplinary open access archive for the deposit and dissemination of scientific research documents, whether they are published or not. The documents may come from teaching and research institutions in France or abroad, or from public or private research centers.
L'archive ouverte pluridisciplinaire HAL, est destinée au dépôt et à la diffusion de documents scientifiques de niveau recherche, publiés ou non, émanant des établissements d'enseignement et de recherche français ou étrangers, des laboratoires publics ou privés. 


\section{1,1,4,4-Tetracyanobutadiene-Functionalized Anthracenes: Regioselectivity of Cycloadditions in the Synthesis of Small Near-IR Dyes}

Clotilde Philippe, Anh Thy Bui, Sabrinah Batsongo-Boulingui, Ziemowit Pokladek, Katarzyna Matczyszyn, Olivier Mongin, Loïc Lemiègre, Frédéric Paul, Trevor A. Hamlin,* and Yann Trolez*

Cite This: Org. Lett. 2021, 23, 2007-2012

Read Online

ACCESS 1

Llll Metrics \& More

Article Recommendations

Supporting Information

ABSTRACT: Two small 1,1,4,4-tetracyanobutadiene-functionalized chromophores were obtained by careful leverage of the regioselectivity of the cycloaddition reaction of tetracyanoethylene with anthracene-ynamide derivatives, inducing either a $[2+2]$ or a $[4+2]$ Diels-Alder process. DFT calculations unraveled the mechanism of the $[2+2]$ cycloaddition-retroelectrocyclization reaction sequence with ynamides and elucidated the differing mechanisms in the two substrates. The synthesized dyes presented panchromatic absorption extending into the near-IR and far-red/ near-IR photoluminescence in the solid state up to $1550 \mathrm{~nm}$.

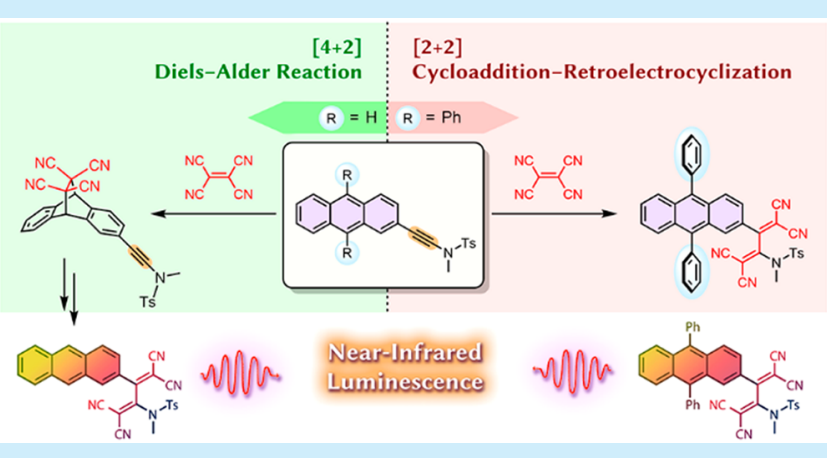

$\mathrm{P}$ ush-pull chromophores, consisting of electron donor and acceptor groups bridged together by a $\pi$-conjugated backbone, are a class of molecules that play a prominent role in organic molecular materials. ${ }^{1}$ Thanks to their particular arrangement that facilitates intramolecular charge transfer (ICT) interactions, they feature in scores of applications including nonlinear optics $(\mathrm{NLO})^{2}$ and organic photovoltaics (OPVs). ${ }^{3}$ This persistently intriguing topic has stimulated the exploration of 1,1,4,4-tetracyanobutadiene (TCBD) derivatives and their chemistry by several groups in the past decade. ${ }^{4-12}$ The elegance of their approach stems from the simplicity of its synthetic route: the TCBD motif can indeed be installed via a facile, high-yield, catalyst-free $[2+2]$ cycloaddition-retroelectrocyclization (CARE) sequence, using tetracyanoethylene (TCNE) and an electron-rich alkyne, ${ }^{10}$ thus allowing for practical synthetic strategies such as postpolymerization functionalizations. ${ }^{13}$ TCBD is now established as a valuable strong electron acceptor group, with a rapidly expanding family of dyes including this motif. Beyond its straightforward incorporation in push-pull chromophores, other advantages of TCBD were put forward: its twisted conformation was shown to increase chromophore solubility and reduce aggregation, thereby improving the poling process efficiency in NLO materials. ${ }^{14}$ Despite a number of studies that have promisingly demonstrated photoinduced charge separation in TCBD-appended chromophores, fast nonradiative deactivation of the excited state in these molecules constitutes a major drawback to their implementation in optoelectronic applica-

tions. As suggested by Armaroli et al., in anilino-TCBDs, torsional motions following photoexcitation give rise to a lowenergy twisted intramolecular charge transfer (TICT) state that can deactivate to the ground state through accessible conical intersections. ${ }^{15}$ As a direct consequence, these molecules are generally nonluminescent and fluorescence that involves a TCBD moiety has seldom been reported. ${ }^{16}$

In an effort to modify the prototypical anilino-TCBD fragment, our group discovered that ynamides can engage in the $[2+2]$-CARE reaction with TCNE to form a sulfonamidoTCBD motif, producing dyes with markedly altered optoelectronic properties. ${ }^{17-19}$ We recently revealed that such chromophores could exhibit near-infrared (NIR) luminescence in the solid state, extending to $1350 \mathrm{~nm} .^{20}$ This surprising result prompted us to further investigate compounds based on a similar design, i.e. sulfonamido-TCBD-PAH (polycyclic aromatic hydrocarbon). Interestingly, others have also described solid-state fluorescence involving an ICT to TCBD in push-pull chromophores bearing a $\mathrm{PAH}^{21}$

While examining the structures of photoactive multicomponent systems that integrate TCBD units, one can

Received: January 13, 2021

Published: February 26, 2021 
remark that anthracene is a strikingly rare building block, with only two examples (to the best of our knowledge) bearing a TCBD motif attached to strong electron-donating groups and remote from the anthracene moiety. ${ }^{22,23}$ A possible explanation is the presence of a competing Diels-Alder (DA) reaction which makes this PAH seemingly incompatible with the $[2+$ 2]-CARE sequence-a pitfall that was also encountered with

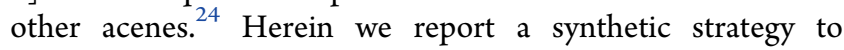
overcome this limitation, a complete mechanistic picture by density functional theory (DFT) calculations, and the optical properties of the synthesized molecules A-TCBD and DPATCBD (Scheme 1).

Scheme 1. Reaction Pathways for the Synthesis of A-TCBD and DPA-TCBD

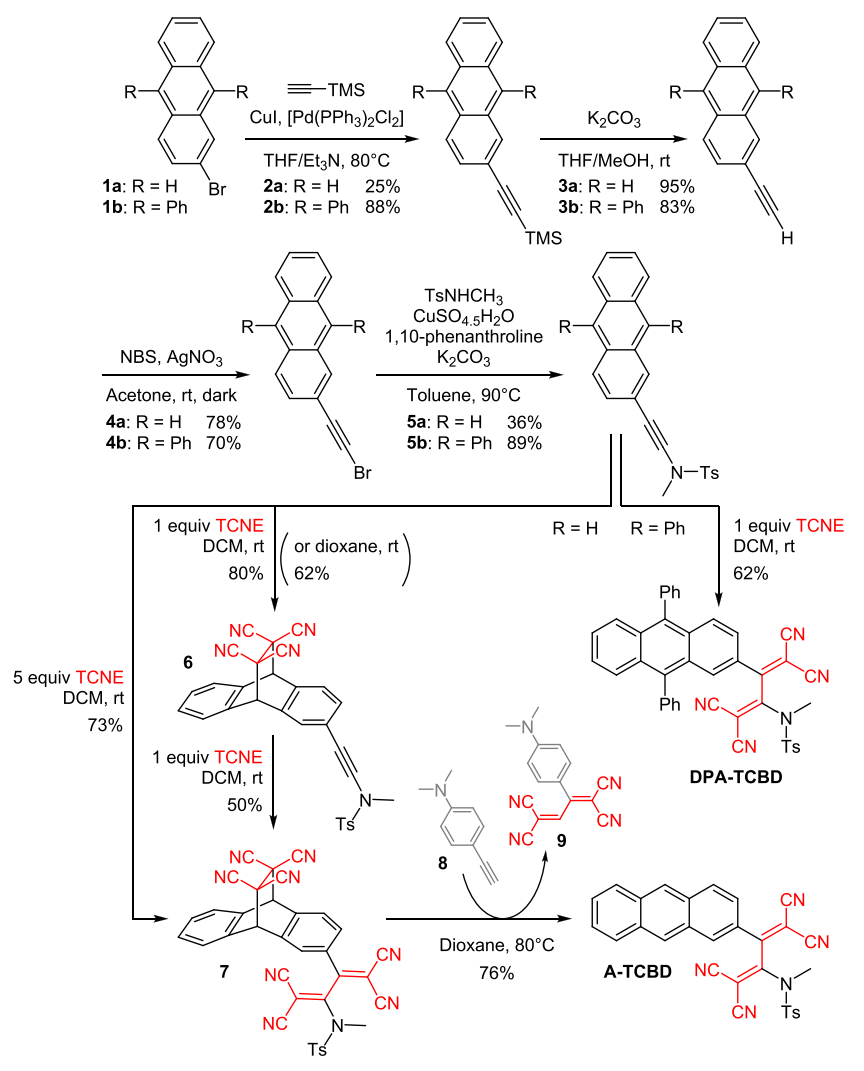

We have previously identified the lack of reactivity of the triple bond when the ynamide is grafted to the 9-position of anthracene, ${ }^{18}$ which prompted us to investigate anthracenes functionalized in a different position. Brominated derivatives $\mathbf{1 a}$ and $\mathbf{1 b}$ were therefore selected as starting molecules to access 2-substituted anthracenes. Sonogashira cross-coupling with trimethylsilylacetylene and subsequent deprotection gave the precursor compounds $3 \mathbf{a}^{25}$ and $\mathbf{3 b}$. The terminal alkynes were brominated to afford compounds $\mathbf{4 a}$ and $\mathbf{4 b}$ in $78 \%$ and $70 \%$ yield, respectively. The latter underwent copper-catalyzed amidation using Hsung's conditions, ${ }^{26}$ leading to ynamides 5a in moderate yield (36\%) and $\mathbf{5 b}$ in very good yield (89\%). Compounds $\mathbf{5} \mathbf{a}$ and $\mathbf{5 b}$ were then reacted with one equivalent of TCNE. While 9,10-diphenylanthracene derivative $\mathbf{5 b}$ yielded DPA-TCBD (62\%), compound A-TCBD was not isolated and the DA product 6 was obtained instead $(80 \%$ yield).

The $[4+2]$ cycloaddition of anthracene with TCNE has already been well documented by several groups. ${ }^{27-29}$ The modulation of the equilibrium for addition of TCNE to anthracene by the solvent was discussed by Brown and Cookson and the dissociation was found to be favored in dioxane. ${ }^{30}$ Furthermore, Sauer et al. demonstrated the recovery of the anthracene addend using a different anthracene derivative to trap $\mathrm{TCNE}^{31}$ In the light of these studies, we sought to harness the reversibility of the DA reaction by testing various methods for the recovery of the anthracene structure and formation of the TCBD group. When 5 a was heated at 80 ${ }^{\circ} \mathrm{C}$ in dioxane in the presence of 1 equiv of TCNE, even though the retro-DA reaction is expected to be feasible under these conditions, the ynamide degraded without significant conversion into A-TCBD. At room temperature, the same reaction led only to cycloadduct 6 in $62 \%$ yield. Under UV irradiation $(365 \mathrm{~nm})$ in toluene, compound 5 a did not provide the $[4+4]$ photodimerization product and its degradation was exclusively observed, invalidating the preliminary protection of the 9,10-positions of the anthracene core by formation of a dimer as an alternate strategy. We endeavored to construct the TCBD motif from cycloadduct 6 instead. In the presence of a second equivalent of TCNE, compound 6 was successfully converted into bisadduct 7 in $50 \%$ isolated yield. Using 5 equiv of TCNE, 5a could be directly transformed into 7 in a much higher yield $(73 \%)$ than through the combined two-step procedure $(40 \%)$. Both cycloaddition products 6 and 7 were moderately stable and decomposed in solution within a few hours. Different conditions for the extrusion of TCNE from the anthracene core were then assessed. When a $0.01 \mathrm{M}$ solution of 7 in dioxane was heated at $80{ }^{\circ} \mathrm{C}$, A-TCBD could be isolated in only $3 \%$ yield after $3 \mathrm{~h}$. To inhibit the forward [ 4 +2 ] cycloaddition, rather than another anthracene derivative and DA reaction, 1.5 equiv of commercially available 4ethynyl- $N, N$-dimethylaniline 8 were used to scavenge extruded TCNE, considering the known efficiency ${ }^{32}$ and irreversibility of the $[2+2]$-CARE reaction. Thus, when stirred for $3 \mathrm{~h}$ at 80 ${ }^{\circ} \mathrm{C}$ in the presence of 8 , a solution of 7 in dioxane provided compound A-TCBD in a satisfactory yield of $76 \%$. The newly synthesized dyes A-TCBD and DPA-TCBD were characterized by ${ }^{1} \mathrm{H}$ and ${ }^{13} \mathrm{C}$ NMR spectroscopy, HRMS, and cyclic voltammetry (Supporting Information).

Density functional theory (DFT) calculations at COSMO(DCM)-BLYP-D3(BJ)/TZ2P using ADF (see the Supporting Information for computational details) were carried out to pinpoint the origin of disparate regioselectivity of $\mathbf{5 a}$ and $\mathbf{5 b}$. For the calculations, the tosyl group (Ts) of $\mathbf{5 a}$ and $\mathbf{5} \mathbf{b}$ was replaced with mesyl group (Ms) and the substrates are denoted as $\mathbf{5 a}^{\prime}$ and $\mathbf{5} \mathbf{b}^{\prime}$. The energy profiles associated with the $[2+2]$-CARE and $[4+2]$ DA sequences of $\mathbf{5} \mathbf{a}^{\prime}$ and $\mathbf{5} \mathbf{b}^{\prime}$ are provided in Figure 1 and are in line with others in the literature. ${ }^{24}$ It can be seen that $\mathbf{5 a}^{\prime}$ preferentially reacts via the $\mathrm{DA}$ sequence, whereas $\mathbf{5} \mathbf{b}^{\prime}$ reacts via the $[2+2]$-CARE sequence. The origin of this observed regioselectivity is traced back to the steric bulk at the 9- and 10-position of the anthracene: the unsubstituted $\mathbf{5 a}^{\prime}$ can facilitate the DA reaction of TCNE at anthracene to afford $6^{\prime}$, whereas the 9,10-diphenylanthracene $\mathbf{5} \mathbf{b}^{\prime}$ is too sterically demanding for the DA reaction and the $[2+2]$-CARE pathway becomes more energetically viable.

First, we focus on the reactivity of the unsubstituted anthracene $\mathbf{5} \mathbf{a}^{\prime}$. The DA sequence of $\mathbf{5} \mathbf{a}^{\prime}$ (Figure 1a, go left) begins with the formation of a reactant complex $\mathbf{5 a}^{\prime}-\mathrm{INT} \mathbf{1}^{*}$ that is more stable (from enhanced $\pi-\pi$ stacking) than the corresponding complex $5 \mathbf{a}^{\prime}$-INT1 of the $[2+2]$-CARE 


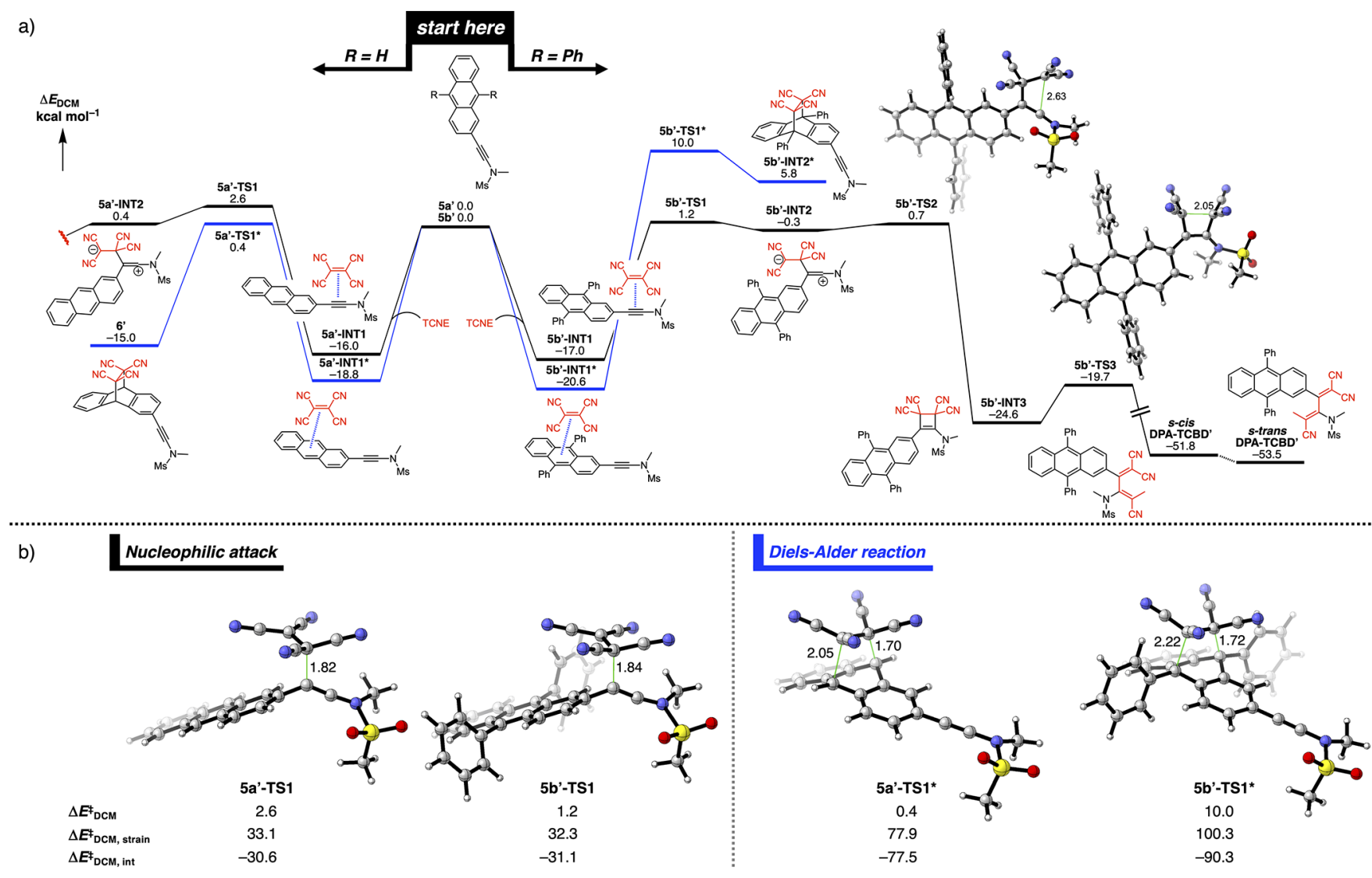

Figure 1. (a) Energy profiles $\left(\Delta E_{\mathrm{DCM}}\right.$ in $\left.\mathrm{kcal} \mathrm{mol}^{-1}\right)$ for the competing catalyst-free $[2+2]$ cycloaddition-retroelectrocyclization (CARE, in black) and $[4+2]$ Diels-Alder (DA) reactions (in blue) of $\mathbf{5 a}^{\prime}$ and $\mathbf{5} \mathbf{b}^{\prime}$ with TCNE; (b) key transition state geometries (in $\AA$ ) and activation strain analysis $\left(\Delta E_{\mathrm{DCM}}^{\ddagger}=\Delta E_{\mathrm{DCM}}^{\ddagger}\right.$, strain $+\Delta E_{\mathrm{DCM}}^{\ddagger}$ int in $\left.\mathrm{kcal} \mathrm{mol}^{-1}\right)$. All data computed at COSMO(DCM)-BLYP-D3(BJ)/TZ2P.

pathway. From $5 \mathbf{a}^{\prime}-\mathrm{INT} \mathbf{1}^{*}$, the DA reaction proceeds through a concerted asynchronous transition state $\mathbf{5 a}^{\prime}-\mathbf{T S} \mathbf{1}^{*}\left(\Delta E^{\ddagger}=\right.$ $\left.0.4 \mathrm{kcal} \mathrm{mol}^{-1}\right)$ to afford the experimentally isolated analog $6^{\prime}$. The first step of the $[2+2]$-CARE sequence involves the nucleophilic attack of $\mathbf{5 a}^{\prime}$ at TCNE, which goes via an

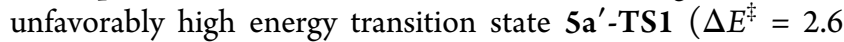

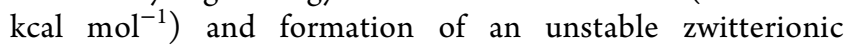
intermediate.

Now, we analyze the reactivity of the 9,10-diphenylanthracene derivative $\mathbf{5} \mathbf{b}^{\prime}$ (Figure 1a, go right). The reactant complex $\mathbf{5} \mathbf{b}^{\prime}$-INT $\mathbf{1}^{*}$ is a resting state on the energy surface and cannot proceed further due to an unsurmountable DA barrier via $5 \mathbf{b}^{\prime}-\mathrm{TS}^{*} *\left(\Delta E^{\ddagger}=10.0 \mathrm{kcal} \mathrm{mol}^{-1}\right)$ that goes with a highly destabilizing strain $\left(\Delta E_{\text {strain }}^{\ddagger}=100.3 \mathrm{kcal} \mathrm{mol}^{-1}\right)$ due to steric clash between TCNE and the phenyl groups at the 9- and 10positions of the anthracene (Figure $1 \mathbf{b}$ ). Instead, $5 \mathbf{b}^{\prime}$-INT $\mathbf{1}^{*}$ reversibly dissociates to the reactants and then can form the slightly less stable $\mathbf{5} \mathbf{b}^{\prime}$-INT $\mathbf{1}$, which undergoes the nucleophilic

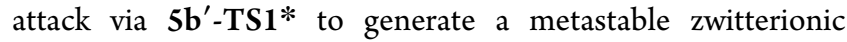
intermediate $\mathbf{5} \mathbf{b}^{\prime}$-INT2. The facile rotation and subsequent cyclization via $\mathbf{5} \mathbf{b}^{\prime}$-TS2 accomplishes the stepwise $[2+2]$ cycloaddition and generates the cycloadduct $5 \mathbf{b}^{\prime}$-INT3. Retrocyclization via $5 \mathbf{b}^{\prime}$-TS3 provides the $\boldsymbol{s}$-cisDPA-TCBD' which can then isomerize to complete the CARE sequence and furnish s-transDPA-TCBD'.

The UV-vis absorption spectra of A-TCBD and DPATCBD were recorded in dichloromethane (Figure 2A). Compared to their ynamide precursors, the clear and characteristic finger-like structured absorption bands of anthracene that were observed between 335 and $400 \mathrm{~nm}$ in $\mathbf{5 a}$ and $\mathbf{5 b}$ are now indistinct. New features arose in both TCBD derivatives, causing their absorption spectra to span the whole visible range. Most remarkably, a very broad and structureless low-energy absorption band, attributed to an ICT transition resulting from interactions between the PAH moiety and TCBD, covers the visible region between 450 and $800 \mathrm{~nm}$, with a maximum located at $527 \mathrm{~nm}\left(\varepsilon=3.5 \times 10^{3} \mathrm{M}^{-1} \mathrm{~cm}^{-1}\right)$ for A-TCBD and at $557 \mathrm{~nm}\left(\varepsilon=4.3 \times 10^{3} \mathrm{M}^{-1} \mathrm{~cm}^{-1}\right)$ for DPA-TCBD. Comparison with published data on pyrene and perylene derivatives decorated with a TCBD unit ${ }^{20}$ reveals a pronounced bathochromic effect as well as a slight hyperchromic effect associated with the increase in the PAH $\pi$ conjugation and/or resonance stabilization (Table S2).

Finally, the photoluminescence (PL) properties of A-TCBD and DPA-TCBD were examined. As reported with analogous dyes, ${ }^{20}$ no emission was detected in dichloromethane, but in rigid media, both compounds displayed a very comparable and broad PL band (Figure 2B). In diluted rigid matrices (2methyltetrahydrofuran at $77 \mathrm{~K}$ and PMMA at room temperature, Table S3), where the intermolecular interactions ${ }^{33}$ are minimized, this band lied between the red and the first nearinfrared window (NIR-I, 700-950 nm). Powders of the products exhibited PL in the NIR-I region with a maximum centered at 865 and $875 \mathrm{~nm}$ for A-TCBD and DPA-TCBD respectively, and a remarkably long tail extending to $1550 \mathrm{~nm}$ in the second near-infrared window (NIR-II, 1000-1700 nm), even farther than the upper limit in pyrene and perylene derivatives (ca. $1350 \mathrm{~nm}$ ). This PL enhancement in the solid- 

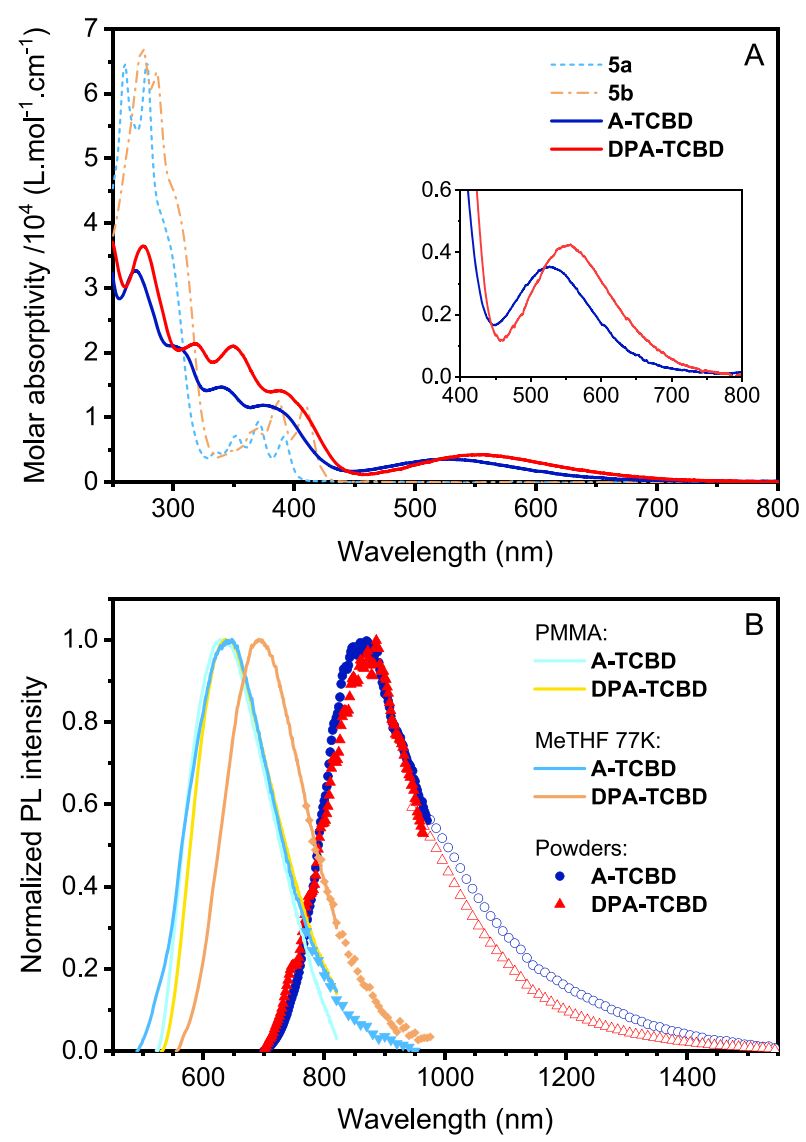

Figure 2. (A) UV-vis absorption spectra of ynamide precursors 5a and $\mathbf{5 b}$ and compounds A-TCBD and DPA-TCBD in dichloromethane. Inset: zoom on the low-energy band of A-TCBD and DPATCBD. (B) Normalized photoluminescence spectra of A-TCBD and DPA-TCBD in PMMA ( $\lambda_{\text {exc }}=500$ and $515 \mathrm{~nm}$, respectively), organic glass (MeTHF at $77 \mathrm{~K}, \lambda_{\text {exc }}=480$ and $520 \mathrm{~nm}$, respectively), and powders $\left(\lambda_{\text {exc }}=585\right.$ and $600 \mathrm{~nm}$, respectively). The different detectors used are represented as follows. Continuous line: R928; filled symbols: R2658; open symbols: InGaAs.

state can be ascribed to the restriction of molecular motions following light absorption, which helps reduce the nonradiative losses in these environments. ${ }^{21}$

Besides the successful synthesis of two TCBD-appended anthracene derivatives A-TCBD and DPA-TCBD, our joined experimental and theoretical investigations showed that the regioselectivity of the cycloaddition reaction of TCNE with 5a and $\mathbf{5 b}$, favoring either $\mathbf{a}[4+2]$ Diels-Alder process with the anthracene core in $5 \mathbf{a}$ or a $[2+2]$-CARE reaction with the triple bond in $\mathbf{5 b}$, is dictated by steric effects at the 9,10 positions. DFT calculations uncovered the mechanism of the $[2+2]$-CARE sequence with ynamides for the first time, demonstrating that the reaction proceeds through stepwise [2 +2 ] cyclization to produce a cyclobutene intermediate which then opens to give the TCBD moiety. When the DA reaction was preferential, it could advantageously be used to deactivate the 9,10-positions prior to the $[2+2]$-CARE, then its reversibility exploited to unmask the anthracene core thanks to a scavenger. In addition to insight into the reactivity of some $\pi$ systems with TCNE, we expect the synthetic method developed to obtain A-TCBD to be applicable to other acene-TCBD targets. Both A-TCBD and DPA-TCBD displayed optical properties that were remarkable for such small dyes. They presented panchromatic absorption in DCM that extends into the NIR-I region, and solid-state PL signals lying between the far-red and the NIR-II range. This latter feature, rare in TCBD-functionalized molecules, thus further substantiates that new molecular designs comprising this fragment can offer room for unusual photophysical properties. $^{34}$

\section{ASSOCIATED CONTENT}

\section{Supporting Information}

The Supporting Information is available free of charge at https://pubs.acs.org/doi/10.1021/acs.orglett.1c00136.

General and synthetic procedures, characterization data, cyclic voltammograms, complementary UV-vis and photoluminescence data, excitation spectra, and full computational details (PDF)

\section{AUTHOR INFORMATION}

\section{Corresponding Authors}

Trevor A. Hamlin - Department of Theoretical Chemistry, Amsterdam Institute of Molecular and Life Sciences (AIMMS), and Amsterdam Center for Multiscale Modeling (ACMM), Vrije Universiteit Amsterdam, $1081 \mathrm{HV}$ Amsterdam, The Netherlands; $\odot$ orcid.org/0000-00025128-1004; Email: t.a.hamlin@vu.nl

Yann Trolez - Univ Rennes, Ecole Nationale Supérieure de Chimie de Rennes, CNRS, ISCR - UMR6226, F-35000 Rennes, France; Oorcid.org/0000-0002-5421-9556; Email: yann.trolez@ensc-rennes.fr

\section{Authors}

Clotilde Philippe - Univ Rennes, Ecole Nationale Supérieure de Chimie de Rennes, CNRS, ISCR - UMR6226, F-35000 Rennes, France

Anh Thy Bui - Univ Rennes, Ecole Nationale Supérieure de Chimie de Rennes, CNRS, ISCR - UMR6226, F-35000 Rennes, France; (1) orcid.org/0000-0002-3718-7652

Sabrinah Batsongo-Boulingui - Univ Rennes, Ecole Nationale Supérieure de Chimie de Rennes, CNRS, ISCR UMR6226, F-35000 Rennes, France

Ziemowit Pokladek - Faculty of Chemistry, Wroclaw University of Science and Technology, 50-370 Wroclaw, Poland

Katarzyna Matczyszyn - Faculty of Chemistry, Wroclaw University of Science and Technology, 50-370 Wroclaw, Poland; orcid.org/0000-0001-8578-8340

Olivier Mongin - Univ Rennes, Ecole Nationale Supérieure de Chimie de Rennes, CNRS, ISCR - UMR6226, F-35000 Rennes, France

Loïc Lemiègre - Univ Rennes, Ecole Nationale Supérieure de Chimie de Rennes, CNRS, ISCR - UMR6226, F-35000 Rennes, France; (1) orcid.org/0000-0001-6622-171X

Frédéric Paul - Univ Rennes, Ecole Nationale Supérieure de Chimie de Rennes, CNRS, ISCR - UMR6226, F-35000 Rennes, France; (1) orcid.org/0000-0002-8256-0129

Complete contact information is available at: https://pubs.acs.org/10.1021/acs.orglett.1c00136

\section{Notes}

The authors declare no competing financial interest. 


\section{ACKNOWLEDGMENTS}

This study is part of the project ANR JCJC Fluotet 17-CE070038-01 from the Agence Nationale pour la Recherche. A.T.B. and C.P. thank the Région Bretagne for funding postdoctoral and doctoral grants, respectively. PHC Polonium 37629XG (2017-2018) is aknowledged for funding. The authors would like to acknowledge Dr. Olivier Maury (Laboratoire de Chimie at ENS de Lyon) for access to the Horiba Jobin-Yvon fluorometers. Dr. François Riobé (Laboratoire de Chimie at ENS de Lyon) is also thanked for assistance with the corresponding measurements and fruitful discussions. T.A.H. thanks The Netherlands Organization for Scientific Research (NWO) for support.

\section{DEDICATION}

This work is dedicated to the memory of François Diederich.

\section{REFERENCES}

(1) Kivala, M.; Diederich, F. Acetylene-Derived Strong Organic Acceptors for Planar and Nonplanar Push-Pull Chromophores. Acc. Chem. Res. 2009, 42 (2), 235-248.

(2) Barlow, S.; Marder, S. R. Nonlinear Optical Properties of Organic Materials. In Functional Organic Materials; Muller, T. J. J., Bunz, U. H. F., Eds.; Wiley-VCH Verlag: Weinheim, Germany, 2006; pp 393-437. DOI: 10.1002/9783527610266.ch11.

(3) Su, Y.-W.; Lan, S.-C.; Wei, K.-H. Organic Photovoltaics. Mater. Today 2012, 15 (12), 554-562.

(4) Mochida, T.; Yamazaki, S. Mono- and Diferrocenyl Complexes with Electron-Accepting Moieties Formed by the Reaction of Ferrocenylalkynes with Tetracyanoethylene. J. Chem. Soc., Dalton Trans. 2002, 18 (18), 3559-3564.

(5) Leliège, A.; Blanchard, P.; Rousseau, T.; Roncali, J. Triphenylamine/Tetracyanobutadiene-Based D-A-D $\pi$-Conjugated Systems as Molecular Donors for Organic Solar Cells. Org. Lett. 2011, 13 (12), 3098-3101.

(6) Koszelewski, D.; Nowak-Król, A.; Gryko, D. T. Selective Cycloaddition of Tetracyanoethene (TCNE) and 7,7,8,8-Tetracyanop-Quinodimethane (TCNQ) to Afford Meso-Substituted Phenylethynyl Porphyrins. Chem. - Asian J. 2012, 7 (8), 1887-1894.

(7) Kato, S.; Noguchi, H.; Jin, S.; Nakamura, Y. Synthesis and Electronic, Optical, and Electrochemical Properties of a Series of Tetracyanobutadiene-Substituted Carbazoles. Asian J. Org. Chem. 2016, 5 (2), 246-256.

(8) Shoji, T.; Ito, S. Azulene-Based Donor-Acceptor Systems: Synthesis, Optical, and Electrochemical Properties. Chem. - Eur. J. 2017, 23 (66), 16696-16709.

(9) Wang, Y.; Michinobu, T. Polymeric Chemosensors: A Conventional Platform with New Click Chemistry. Bull. Chem. Soc. Jpn. 2017, 90 (12), 1388-1400.

(10) Michinobu, T.; Diederich, F. The $[2+2]$ CycloadditionRetroelectrocyclization (CA-RE) Click Reaction: Facile Access to Molecular and Polymeric Push-Pull Chromophores. Angew. Chem., Int. Ed. 2018, 57 (14), 3552-3577.

(11) Patil, Y.; Misra, R. Rational Molecular Design towards NIR Absorption: Efficient Diketopyrrolopyrrole Derivatives for Organic Solar Cells and Photothermal Therapy. J. Mater. Chem. C 2019, 7 (42), 13020-13031.

(12) Shoji, T.; Okujima, T.; Ito, S. Development of HeterocycleSubstituted and Fused Azulenes in the Last Decade (2010-2020). Int. J. Mol. Sci. 2020, 21 (19), 7087.

(13) Li, Y.; Ashizawa, M.; Uchida, S.; Michinobu, T. Colorimetric Sensing of Cations and Anions by Clicked Polystyrenes Bearing Side Chain Donor-Acceptor Chromophores. Polym. Chem. 2012, 3 (8), 1996-2005.

(14) Wu, X.; Wu, J.; Liu, Y.; Jen, A. K.-Y. Highly Efficient, Thermally and Chemically Stable Second Order Nonlinear Optical Chromo- phores Containing a 2-Phenyl-Tetracyanobutadienyl Acceptor. J. Am. Chem. Soc. 1999, 121, 472-473.

(15) Monti, F.; Venturini, A.; Nenov, A.; Tancini, F.; Finke, A. D.; Diederich, F.; Armaroli, N. Anilino-Substituted Multicyanobuta-1,3Diene Electron Acceptors: TICT Molecules with Accessible Conical Intersections. J. Phys. Chem. A 2015, 119 (43), 10677-10683.

(16) Perhaps the most notable description of this type of fluorescence concerns an intramolecular exciplex emission: Winterfeld, K. A.; Lavarda, G.; Guilleme, J.; Sekita, M.; Guldi, D. M.; Torres, T.; Bottari, G. Subphthalocyanines Axially Substituted with a Tetracyanobuta-1,3-Diene-Aniline Moiety: Synthesis, Structure, and Physicochemical Properties. J. Am. Chem. Soc. 2017, 139 (15), 5520-5529. For other interesting reports, see, for example: Xu, J.; Liu, X.; Lv, J.; Zhu, M.; Huang, C.; Zhou, W.; Yin, X.; Liu, H.; Li, Y.; Ye, J. Morphology Transition and Aggregation-Induced Emission of an Intramolecular Charge-Transfer Compound. Langmuir 2008, 24 (8), 4231-4237. Dar, A. H.; Gowri, V.; Gopal, A.; Muthukrishnan, A.; Bajaj, A.; Sartaliya, S.; Selim, A.; Ali, Md. E.; Jayamurugan, G. Designing of Push-Pull Chromophores with Tunable Electronic and Luminescent Properties Using Urea as the Electron Donor. J. Org. Chem. 2019, 84 (14), 8941-8947.

(17) Betou, M.; Kerisit, N.; Meledje, E.; Leroux, Y. R.; Katan, C.; Halet, J.-F.; Guillemin, J.-C.; Trolez, Y. High-Yield Formation of Substituted Tetracyanobutadienes from Reaction of Ynamides with Tetracyanoethylene. Chem. - Eur. J. 2014, 20 (31), 9553-9557.

(18) Betou, M.; Durand, R. J.; Sallustrau, D. A.; Gousset, C.; Le Coz, E.; Leroux, Y. R.; Toupet, D. L.; Trzop, E.; Roisnel, T.; Trolez, Y. Reactivity of Functionalized Ynamides with Tetracyanoethylene: Scope, Limitations and Optoelectronic Properties of the Adducts. Chem. - Asian J. 2017, 12 (12), 1338-1346.

(19) Bouvier, R.; Durand, R.; Favereau, L.; Srebro-Hooper, M.; Dorcet, V.; Roisnel, T.; Vanthuyne, N.; Vesga, Y.; Donnelly, J.; Hernandez, F.; Autschbach, J.; Trolez, Y.; Crassous, J. Helicenes Grafted with 1,1,4,4-Tetracyanobutadiene Moieties: $\pi$-Helical PushPull Systems with Strong Electronic Circular Dichroism and TwoPhoton Absorption. Chem. - Eur. J. 2018, 24 (54), 14484-14494.

(20) Bui, A. T.; Philippe, C.; Beau, M.; Richy, N.; Cordier, M.; Roisnel, T.; Lemiègre, L.; Mongin, O.; Paul, F.; Trolez, Y. Synthesis, Characterization and Unusual near-Infrared Luminescence of 1,1,4,4Tetracyanobutadiene Derivatives. Chem. Commun. 2020, 56 (24), 3571-3574.

(21) Simón Marqués, P.; Castan, J. M. A.; Raul, B. A. L.; Londi, G.; Ramirez, I.; Pshenichnikov, M. S.; Beljonne, D.; Walzer, K.; Blais, M.; Allain, M.; Cabanetos, C.; Blanchard, P. Triphenylamine/Tetracyanobutadiene-based П-Conjugated Push-Pull Molecules End-capped with Arene Platforms: Synthesis, Photophysics, and Photovoltaic Response. Chem. - Eur. J. 2020, 26, chem.202002810.

(22) Gautam, P.; Misra, R.; Siddiqui, S. A.; Sharma, G. D. Unsymmetrical Donor-Acceptor-Acceptor- $\pi$-Donor Type Benzothiadiazole-Based Small Molecule for a Solution Processed Bulk Heterojunction Organic Solar Cell. ACS Appl. Mater. Interfaces 2015, 7 (19), 10283-10292.

(23) Rout, Y.; Mobin, S. M.; Misra, R. Tetracyanobutadiene (TCBD) Functionalized Benzothiadiazole Derivatives: Effect of Donor Strength on the $[2+2]$ Cycloaddition-Retroelectrocyclization Reaction. New J. Chem. 2019, 43 (31), 12299-12307.

(24) Lehnherr, D.; Adam, M.; Murray, A. H.; McDonald, R.; Hampel, F.; Tykwinski, R. R. Synthesis, Physical Properties, and Chemistry of Donor-Acceptor-Substituted Pentacenes. Can. J. Chem. 2017, 95 (3), 303-314.

(25) Back, J. Y.; An, T. K.; Cheon, Y. R.; Cha, H.; Jang, J.; Kim, Y.; Baek, Y.; Chung, D. S.; Kwon, S.-K.; Park, C. E.; Kim, Y.-H. Alkyl Chain Length Dependence of the Field-Effect Mobility in Novel Anthracene Derivatives. ACS Appl. Mater. Interfaces 2015, 7 (1), 351358.

(26) Zhang, Y.; Hsung, R. P.; Tracey, M. R.; Kurtz, K. C. M.; Vera, E. L. Copper Sulfate-Pentahydrate-1,10-Phenanthroline Catalyzed Amidations of Alkynyl Bromides. Synthesis of Heteroaromatic Amine Substituted Ynamides. Org. Lett. 2004, 6 (7), 1151-1154. 
(27) Middleton, W. J.; Heckert, R. E.; Little, E. L.; Krespan, C. G. Cyanocarbon Chemistry. III. 1 Addition Reactions of Tetracyanoethylene. J. Am. Chem. Soc. 1958, 80 (11), 2783-2788.

(28) Masci, B.; Pasquale, S.; Thuéry, P. Supramolecular Control of a Fast and Reversible Diels-Alder Reaction. Org. Lett. 2008, 10 (21), $4835-4838$.

(29) Ronson, T. K.; Pilgrim, B. S.; Nitschke, J. R. PathwayDependent Post-Assembly Modification of an Anthracene-Edged $\mathrm{M}^{\mathrm{II}}$ ${ }_{4}$ L 6 Tetrahedron. J. Am. Chem. Soc. 2016, 138 (33), 10417-10420. (30) Brown, P.; Cookson, R. C. Kinetics of Addition of Tetracyanoethylene to Anthracene and Bicyclo[2,2,1]Heptadiene. Tetrahedron 1965, 21 (8), 1977-1991.

(31) Sauer, J.; Schröder, B.; Wiemer, R. Eine Studie der Diels-AlderReaktion, VI. Kinetischer Nachweis des Moleküls C6O6 (Dianhydrid der Äthylentetracarbonsäure). Chem. Ber. 1967, 100 (1), 306-314.

(32) Michinobu, T.; Boudon, C.; Gisselbrecht, J.-P.; Seiler, P.; Frank, B.; Moonen, N. N. P.; Gross, M.; Diederich, F. DonorSubstituted 1,1,4,4-Tetracyanobutadienes (TCBDs): New Chromophores with Efficient Intramolecular Charge-Transfer Interactions by Atom-Economic Synthesis. Chem. - Eur. J. 2006, 12 (7), 1889-1905.

(33) Salamatova, E.; Kozlov, O. V.; Luponosov, Y. N.; Solodukhin, A. N.; Toropynina, V. Y.; Ponomarenko, S. A.; Pshenichnikov, M. S. Visualization of Molecular Excitons Diffusion. In Proc. SPIE Nanoscience + Engineering Conference; Bakulin, A. A., Lovrincic, R., Banerji, N., Eds.; San Diego, 2016; p 99230K. DOI: 10.1117/ 12.2237620

(34) Philippe, C.; Bui, A. T.; Batsongo-Boulingui, S.; Pokladek, Z.; Matczyszyn, K.; Mongin, O.; Lemiègre, L.; Paul, F.; Hamlin, T.; Trolez, Y. 1,1,4,4-Tetracyanobutadiene-Functionalized Anthracenes: Regioselectivity of Cycloadditions in the Synthesis of Small Near-IR Dyes. ChemRxiv 2020, DOI: 10.26434/chemrxiv.13491135.v1. 